\title{
Cooperativismo agroindustrial: diagnóstico atual da região centro-oeste brasileira
}

\author{
Agroindustrial cooperativism: brazilian central-west region's current diagnosis
}

\begin{abstract}
Resumo
O cooperativismo é apontado por diversos setores da sociedade, juntamente com algumas correntes acadêmicas, como um modelo de desenvolvimento mais justo e inclusivo. Neste contexto, o Centro-Oeste brasileiro figura em posição de destaque dentro do agronegócio. De acordo com dados da Organização das Cooperativas do Brasil (OCB), aproximadamente 50\% do agronegócio do Centro-Oeste passam, de alguma forma, por uma cooperativa. Assim, o principal objetivo deste trabalho é contextualizar o cooperativismo agroindustrial no Centro-Oeste brasileiro. Como objetivos secundários citam-se: a) traçar um breve histórico do cooperativismo; b) e contextualizar o ramo agroindustrial dentro do cooperativismo. Os métodos empregados para tanto foram levantamento bibliográfico e análise documental. O cenário que se desenha mostra tendências à concentração no setor agroindustrial, onde as grandes e tradicionais cooperativas aparentam estar ficando cada vez maiores e mais sólidas, especialmente, no que tange à produção de grãos.
\end{abstract}

Palavras-chave: cooperativa, agronegócio, princípios do cooperativismo.

\begin{abstract}
Cooperativism is pointed out by several society sectors, along with some academic currents, as a fairer and inclusive development model. Brazilian Midwest is prominent in agribusiness. According to data of Brazilian Cooperatives' Organization ( $\mathrm{OCB}$ ), approximately 50\% of the Midwest's agribusiness has contributions of cooperatives. Thus, this article's main objective is to contextualize agroindustrial cooperativism in the Brazilian Midwest. Secondary objectives include: a) cooperativism's brief history; b) and contextualize the agroindustrial segment within cooperativism. Bibliographic survey and documentary analysis were the methods employed. The current scenario shows concentration in the agroindustrial sector, where large and traditional cooperatives appear to be getting bigger and stronger, especially in grain production.
\end{abstract}

Keywords: cooperative, agribusiness, cooperativism principles.

Osmar de Paula Oliveira Júnior ${ }^{\mathrm{I}}$, Alcido Elenor Wander ${ }^{\mathrm{II}}$.

${ }^{\mathrm{I}}$ Universidade Federal de Goiás - UFG. Goiás, GO. juniorfaj@yahoo.com.br

${ }^{\text {II }}$ Empresa Brasileira de Pesquisa Agropecuária-EMBRAPA. alcido.wander@embrapa.br 


\section{Introdução}

O cooperativismo é apontado por diversos setores da sociedade, juntamente com algumas correntes acadêmicas, como um modelo de desenvolvimento mais justo e inclusivo. Isto se deve ao fato de que este se baseia no trabalho coletivo em detrimento do capital, como ocorre na lógica de desenvolvimento dominante, o capitalismo.

De acordo com dados do Serviço Nacional de Aprendizagem do Cooperativismo-SESCOOP (2017), o Brasil conta com 6,6 mil cooperativas em atividade, sendo que, aproximadamente $60 \%$ destas, estão ligadas a atividades primárias, tais como agricultura, pesca e artesanato. Segundo informações da Organização das Cooperativas Brasileiras (OCB, 2017a), o cooperativismo é responsável por aproximadamente $11 \%$ do Produto Interno Bruto (PIB) agropecuário no Brasil, empregando diretamente, neste setor, 180,1 mil pessoas em 1.543 cooperativas com 993,5 mil cooperados. Estes dados ajudam a evidenciar o papel do cooperativismo como instrumento de desenvolvimento socioeconômico.

À primeira vista, os números parecem satisfatórios. No entanto, analisando-os sob uma ótica mais ampla, percebe-se que ainda há muito a se fazer. Num universo de mais de 6 milhões de empresas tradicionais em atividade no Brasil (IBGE, 2017), 6,6 mil cooperativas passam a parecer um número modesto. Ademais, de acordo com estatísticas da própria OCB (2017a), o número de cooperativas se mostra estagnado nos últimos 15 anos, sendo que houve, sim, um saldo negativo de 193 entidades. Ou seja, observando os dados, percebe-se que fecham mais cooperativas do que se abrem.

Neste cenário, a região Centro-Oeste figura em posição de destaque dentro do agronegócio brasileiro. Segundo dados da Companhia Nacional de Abastecimento-CONAB (2019a), o CentroOeste deverá, mais uma vez, liderar a produção de grãos nacional na safra 2018/2019, com uma produção total estimada em 107,2 milhões de toneladas, com destaque especial ao estado de Mato Grosso, que é o maior produtor de grãos do país, tendo a produção estimada em de 64,5 milhões de toneladas para esta safra. Os principais grãos produzidos são a soja e o milho. A região também é a segunda maior produtora de cana-de-açúcar, com uma previsão de 137 milhões de toneladas (CONAB, 2019b). Neste quesito destaca-se o estado de Goiás, onde se espera que o volume chegue a 70 milhões de toneladas na safra 2018/2019. De acordo com a Empresa Brasileira de Pesquisa Agropecuária (EMBRAPA, 2019), Goiás também responde pela quinta maior produção de leite entre os estados brasileiros.

As 175 cooperativas agroindustriais sediadas no Centro-Oeste oferecem grande contribuição para o sucesso do agronegócio nesta região. De acordo com dados da OCB (2019), aproximadamente $50 \%$ da produção do agronegócio do Centro-Oeste passam, de alguma forma, por uma cooperativa. Assim, é possível perceber a importância do cooperativismo agroindustrial para a economia regional, sendo que este constitui o principal instrumento de organização e empoderamento dos produtores rurais locais.

Deste modo, conhecer as condições em que o cooperativismo agroindustrial do Centro-Oeste se encontra, constitui o ponto de partida para a compreensão dos principais desafios e oportunidades com os quais a atividade deverá se defrontar nos próximos anos, bem como caminhos para prováveis soluções. Igualmente, tem-se a possibilidade de fomentar novas pesquisas versando sobre o tema, o que poderá contribuir para o desenvolvimento da ciência no campo do cooperativismo agroindustrial. Assim, o principal objetivo deste trabalho é: contextualizar o cooperativismo agroindustrial no Centro-Oeste Brasileiro. Como objetivos secundários citam-se: a) traçar um breve histórico do cooperativismo; b) e contextualizar o ramo agroindustrial dentro do cooperativismo. 
Para tanto, buscaram-se analisar obras clássicas e atuais relevantes para a literatura nacional e internacional versando sobre os temas aqui abordados. Também, consultaram-se dados secundários disponíveis em publicações realizadas pela Organização das Cooperativas BrasileirasOCB, em especial, as unidades sediadas nos estados da região Centro-Oeste e pelo Instituto Brasileiro de Geografia e Estatística-IBGE. Os métodos empregados, portanto, foram levantamento bibliográfico e análise documental.

\section{Procedimentos Metodológicos}

Como métodos, para a realização deste estudo, empregaram-se a pesquisa bibliográfica e o levantamento de dados secundários. Inicialmente, para a redação do referencial teórico, realizaramse, no período de fevereiro a março de 2019, buscas em portais de conteúdo acadêmico relevantes: Portal de Periódicos da CAPES, Scientific Electronic Library Online-SciELO e Scopus. Como filtros, buscou-se encontrar trabalhos que continham no título, resumo ou palavras-chave, os termos: cooperativismo, cooperativa, agropecuária, agroindustrial, Centro-Oeste, Goiás, Mato Grosso, Mato Grosso do Sul e Distrito Federal. Também, quando possível, empregaram-se os termos no plural e nos idiomas inglês e espanhol. Após a leitura dos resumos, selecionaram-se 20 obras consideradas relevantes, as quais serviram como base teórica para este artigo. Igualmente, realizaram-se buscas nas bibliotecas: Central da Universidade Federal de Goiás e da Organização das Cooperativas Brasileiras-OCB, buscando-se identificar obras clássicas ou técnicas, as quais pudessem contribuir com este estudo.

Com relação aos dados secundários, destinados à descrição da situação atual do cooperativismo agroindustrial na região Centro-Oeste, estes foram coletados junto à Organização das Cooperativas Brasileiras, principalmente suas unidades sediadas em cada um dos estados pertencentes, bem como ao Instituto Brasileiro de Geografia e Estatística-IBGE. No que se refere ao Estado de Goiás, tomou-se como base o Censo do Cooperativismo Goiano 2018. Igualmente, com ralação a Mato Grosso do Sul, contou-se com a publicação promovida, anualmente, pela OCB local, denominada Panorama do Cooperativismo Sul-Mato-Grossense 2018. Quanto ao estado de Mato Grosso e Distrito Federal, utilizaram-se, como base, dados publicados nos portais on-line das OCBs locais, sendo que, como fontes de informações complementares, estabeleceram-se contatos via email com as organizações, as quais cooperaram, na medida do possível, com a pesquisa.

\section{Cooperativismo: Conceitos, Ideias e História}

Pinho (1966) explica que o cooperativismo é o sistema, doutrina ou ideologia, cuja cooperativa é a unidade ou entidade onde as pessoas cooperam objetivando fins comuns. Assim, pode-se afirmar que o cooperativismo é a corrente de pensamento que deu base teórica às realizações cooperativistas, ao passo que a cooperativa é o locus onde a cooperação efetivamente acontece.

Para Schneider (1981), o surgimento do cooperativismo está ligado à busca por uma solução pacífica como resposta às falhas apresentadas pelo modelo capitalista. Já Bonin et al. (1993), afirmam que a criação de cooperativas, normalmente, está ligada à busca, por parte dos trabalhadores, ou pequenos produtores, de melhores condições de vida e remuneração.

O ideal de cooperativismo surgiu da constatação de que fazer as coisas junto com outras pessoas (cooperação) era o meio mais viável para encontrar as soluções interessantes a determinados grupos de indivíduos (RICCIARDI; LEMOS, 200o). Isto porque o cooperativismo constitui um sistema econômico diferenciado, onde o trabalho domina o capital econômico, assim, pode-se dizer que se trata de uma doutrina econômica que privilegia o social. Desse modo, o ideal cooperativista surge como uma solução alternativa ao modus operandi do capitalismo tradicional, cuja lógica se baseia na exploração do trabalho assalariado. 
Rios (2007) argumenta que o surgimento do cooperativismo está ligado ao desenvolvimento do capitalismo industrial na Europa do século XVIII. O autor define o cooperativismo como uma reação do movimento operário às condições de extrema exploração então vigentes. Neste sentido, a doutrina cooperativista seria uma tentativa de se instituir um modelo de desenvolvimento mais justo e igualitário.

O movimento cooperativista surgiu na década de 1830, na Inglaterra, mais precisamente na cidade de Rochdale, quando um pequeno grupo de artesãos fundou a Rochdale Friendly Co-operative Society. Na ocasião, a Europa estava inserida em um contexto de tensão social, agravado pelas consequências desencadeadas pela Revolução Industrial. A nova ordem produtiva, baseada na intensificação do capital, dizimou os pequenos negócios artesanais, elevou os índices de desemprego e levou à diminuição da remuneração média paga os trabalhadores em troca de jornadas de trabalho mais longas. Enquanto a classe artesã via o seu poder de compra se esfacelar, camponeses eram expulsos de suas terras, ocasionando severos problemas socioeconômicos para toda a população (DELARMELINA; SALLES, 2016). Tais dificuldades se agravaram, segundo Fairbairn (1994), em função do comportamento oportunista apresentado pelos comerciantes da época, os quais se aproveitavam da situação desfavorável dos trabalhadores para praticar preços abusivos, vender produtos adulterados ou oferecer armadilhas creditícias.

Em decorrência dessa condição de stress socioeconômico, cada vez mais agravado nos anos seguintes, a doutrina cooperativista iniciou a sua expansão (ZEULI; CROPP, 2008). Assim, em 1844, um grupo de 28 artesãos ingleses, pertencentes ao distrito de Lancashire, fundou a Rochdale Society of Equitable Pionners, que mais tarde seria conhecida como "Pioneiros da Rochdale", marcando o início da explosão do cooperativismo na Europa (PINHO, 1966). O objetivo dos fundadores era adquirir bens de consumo de melhor qualidade e mais baratos, repassando as condições mais favoráveis aos próprios associados no momento da comercialização, constituindo-se, portanto, em uma cooperativa de consumo (ANTONIALLI; SOUKI, 2005). Segundo Delarmelina e Salles (2016), o grupo era motivado por objetivos econômicos (fornecimento de bens de consumo e alimentos a preços acessíveis, criação de local específico para a comercialização, organização e distribuição da produção) e sociais (melhores condições de trabalho moradia e educação para os associados). Os valores e regras defendidos pelos Pioneiros da Rochdale viriam a se tornar a base da doutrina cooperativista, sendo que sua influência ainda está presente no sistema atual.

Alguns anos mais tarde, já na década de 1850, os Pioneiros da Rochdale começaram a expansão de suas atividades com a criação da Co-operative Corn Mill Society, um moinho de farinha, cuja propriedade era dividida com outras cinco associações. Também foi fundada a Rochdale Cooperative Manufacturing Society, cujas instalações contavam com mais de 90 teares (FAIRBAIRN, 1994).

As cooperativas de consumo só foram legalmente sancionadas na Inglaterra em 1852 (ALTMAN, 2016). Desde então, a exemplo dos Pioneiros da Rochdale, elas foram se multiplicando, sendo que, no início dos anos 1860, já havia aproximadamente 500 unidades operando em todo o território inglês (DELARMELINA; SALLES, 2016).

A partir das experiências e sucessos do modelo iniciado na Inglaterra, o cooperativismo se difundiu para diversos outros países, estando presente em praticamente todo o mundo. Fairbairn (1994) assevera que o movimento cooperativista foi responsável por importantes transformações socioeconômicas nos locais por onde passou. Em nível mundial, está atrelado à ideia de um novo modelo de desenvolvimento, baseado em princípios de sustentabilidade social.

Gagliardi (2009) apresenta, em seu trabalho, um estudo sobre o desenvolvimento do cooperativismo em diversos países europeus: ex-Iugoslávia, Polônia, Bélgica, Países Baixos, Dinamarca, Alemanha, França, Itália e Espanha, além de Japão e Estados Unidos. O quadro 1 resume 
as principais características do movimento em cada uma dessas nações e acrescenta informações a respeito de Argentina, Uruguai e Chile, considerados casos de destaque na América do Sul.

Quadro 1 - O cooperativismo ao redor do mundo.

\begin{tabular}{|c|c|}
\hline $\begin{array}{c}\text { Ex- } \\
\text { Iugoslávia }\end{array}$ & $\begin{array}{l}\text { Apesar da forte intervenção do Estado (comunista), o movimento } \\
\text { cresceu e ganhou importância a partir dos anos 50, sendo que, em } 1980 \text { as } \\
\text { Organizações Básicas de Trabalho Associado eram responsáveis por } 85 \% \text { do } \\
\text { PIB. }\end{array}$ \\
\hline Polônia & $\begin{array}{l}\text { O movimento se desenvolveu de maneira notável, sendo apoiado pela } \\
\text { igreja e Estado. Possui grande importância, não só econômica, mas também } \\
\text { política e social, especialmente na área rural. }\end{array}$ \\
\hline Bélgica & $\begin{array}{l}\text { O cooperativismo jamais alcançou posição expressiva na Bélgica. Tal } \\
\text { fato se deve a problemas relacionados à legislação, restrição de cooperativas em } \\
\text { alguns segmentos industriais e deficiências no sistema de crédito. }\end{array}$ \\
\hline Países Baixos & $\begin{array}{l}\text { As cooperativas apresentam desempenho semelhante ao das empresas } \\
\text { convencionais, apesar do setor não apresentar números expressivos. }\end{array}$ \\
\hline Dinamarca & $\begin{array}{l}\text { Não há regulação específica nem apoio institucional que leve em } \\
\text { conta as particularidades do cooperativismo. Igualmente, existem severas } \\
\text { restrições quanto ao financiamento de empreendimentos cooperativos. }\end{array}$ \\
\hline Alemanha & $\begin{array}{l}\text { O setor possui grande peso na economia e valorização por parte da } \\
\text { sociedade. Seu desenvolvimento se deve, particularmente, a um aparato } \\
\text { jurídico e legal o qual proporcionou um ambiente institucional bastante } \\
\text { favorável. }\end{array}$ \\
\hline França & $\begin{array}{l}\text { O cooperativismo francês é marcado por uma forte intervenção do } \\
\text { Estado. Apesar de desenvolvida, a atividade nunca chegou a representar um } \\
\text { papel significativo na economia. }\end{array}$ \\
\hline Itália & $\begin{array}{l}\text { A Itália possui o maior setor cooperativo dentre os países da Europa } \\
\text { Ocidental. O cooperativismo representa um importante componente do } \\
\text { sistema econômico deste país. O Estado interveio no sentido de criar um } \\
\text { ambiente institucional favorável. }\end{array}$ \\
\hline Espanha & $\begin{array}{l}\text { O setor é bastante desenvolvido, embora esteja concentrado em } \\
\text { algumas regiões. Graças à legislação diferenciada e programas de } \\
\text { financiamento específicos as cooperativas encontraram o ambiente ideal para } \\
\text { crescer e prosperar. }\end{array}$ \\
\hline Japão & $\begin{array}{l}\text { Os incentivos governamentais, em forma de legislação específica, } \\
\text { políticas de incentivo e financiamento, foram constantes com vistas à criação } \\
\text { de cooperativas locais. }\end{array}$ \\
\hline Estados Unidos & $\begin{array}{l}\text { O setor é bem desenvolvido, particularmente no segmento agrícola. } \\
\text { Isto se deve, especialmente, à criação de um abrangente Sistema de Crédito, } \\
\text { que fornece ampla gama de financiamentos e outros serviços financeiros aos } \\
\text { empreendimentos cooperados. }\end{array}$ \\
\hline Argentina & $\begin{array}{l}\text { Na última década, se encontra em recuperação, porém as cooperativas } \\
\text { mais longevas, criadas antes da década de 50, respondem por } 77 \% \text { do } \\
\text { faturamento do setor. }\end{array}$ \\
\hline Uruguai & $\begin{array}{l}\text { Nos últimos } 10 \text { anos, o número de cooperativas operando em } \\
\text { território uruguaio triplicou. Esse sucesso se deve à adoção de políticas } \\
\text { públicas que incentivam a criação e desenvolvimento de cooperativas. }\end{array}$ \\
\hline Chile & $\begin{array}{l}\text { Embora } 17 \% \text { das cooperativas ativas operem no segmento } \\
\text { agroindustrial, somente o cooperativismo de poupança e crédito possui } \\
\text { representatividade significativa na economia chilena }(70 \%) \text {. }\end{array}$ \\
\hline
\end{tabular}

Fonte: elaborado pelo autor com base em Gagliardi (2009); Lopes (2012); Arocas et al. (2003); e Azerêdo et al. (2018).

No Brasil, o cooperativismo se iniciou no final do século XIX, tendo como marco a criação da Cooperativa Econômica dos Funcionários Públicos de Ouro Preto, em 1889 (OCB, 2018a). Tratava-se de uma cooperativa de consumo, voltada para a obtenção de produtos agrícolas. A partir daí os

empreendimentos cooperados se difundiram para os estados de Minas Gerais, São Paulo, Rio de Janeiro e Rio Grande do Sul, sendo que as cooperativas estão presentes em todo o país, com destaque para as atividades agropecuárias, de crédito, habitação e transportes. 
Em 1971, com o advento da lei 5.764, instituíram-se as normas para a criação de cooperativas mediante o estabelecimento de regime jurídico próprio. A legislação brasileira, de fundamentação rochdaleana, procurou preservar os princípios originais idealizados pelos Pioneiros da Rochdale (ANTONIALLI; SOUKI, 2005). Um ano antes, em 1970, fora fundada a entidade representativa do cooperativismo no Brasil, a Organização das Cooperativas Brasileiras (OCB).

Lopes (2012) assevera que os números do cooperativismo brasileiro não são desprezíveis (37\% do PIB agropecuário tem origem em empreendimentos cooperados, por exemplo), porém estes deveriam ser ainda mais expressivos e conseguidos com menores sacrifícios por parte dos cooperados. Para o autor, os maiores entraves ao pleno desenvolvimento do setor, no Brasil, estão ligados a políticas públicas deficientes e fatores culturais, relacionados com a não valorização do cooperativismo pela maior parte da população.

De acordo com Altman (2016), o movimento cooperativo moderno procura seguir uma série de princípios claros e coerentemente articulados pelos Pioneiros da Rochdale. Tais princípios são definidos como linhas de orientação por meio das quais as cooperativas colocam seus valores em prática (FAIRBAIRN, 1994; ANTONIALLI; SOUKI, 2005; ACI, 2018; OCB, 2018b). Originalmente, foram concebidos doze (ZEULI; CROPP, 2008), porém, após o Congresso de Viena, organizado pela Aliança Cooperativa Internacional (ACI), em 1966, foram referendados sete princípios essenciais, a saber, os quais seriam capazes de manter a efetividade do cooperativismo, bem como preservar os principais pontos de sua ideologia, em um futuro previsível (FAIRBAIRN, 1994; THOMPSON, 1996; ALTMAN, 2016; ACI, 2018; OCB, 2018b):

I- $\quad$ Adesão livre e voluntária: cooperativas são organizações voluntárias e abertas a todos aqueles que estejam aptos a usar os seus serviços e dispostos a aceitar as responsabilidades como membros. Não há discriminação social, racial, política, religiosa ou de gênero;

II- Gestão democrática: os empreendimentos cooperados são democráticos e gerenciados por seus membros, os quais participam ativamente das decisões e concepção de políticas. Os representantes oficiais são eleitos democraticamente pelos membros e se responsabilizam perante estes. Em cooperativas primárias, os membros possuem igual direito a voto (um membro, um voto), sendo que, organizações de outros níveis, também são geridas de forma democrática;

III- Participação econômica dos membros: os cooperados contribuem de maneira equitativa e controlam democraticamente o capital. Normalmente, parte do montante é propriedade comum da cooperativa e os membros recebem remuneração proporcional ao capital integralizado, caso exista. As sobras podem ganhar as seguintes destinações: desenvolvimento da cooperativa, formação de reservas, benefícios para os membros e apoio a outras atividades aprovadas pelos membros;

IV- Autonomia e independência: cooperativas são organizações de ajuda mútua controladas por seus membros. Caso celebrem acordos com outras entidades, sejam elas públicas ou privadas, devem fazê-lo em termos que preservem a gestão democrática e a autonomia;

V- Educação, formação e informação: as cooperativas promovem a educação e formação para seus membros, representantes eleitos, gestores e empregados, de modo que estes possam contribuir para o desenvolvimento da organização. Elas também fornecem informações para a sociedade em geral, além de promover as ideias e vantagens do cooperativismo, em especial para os jovens; 
VI- Intercooperação: para servir melhor aos seus membros, bem como fortalecer o movimento, as cooperativas procuram atuar de maneira conjunta. Elas se unem em organizações, regionais, nacionais e, até mesmo, internacionais, sempre na busca pelo bem comum.

VII- Interesse pela comunidade: as cooperativas, através de políticas aprovadas por seus membros, atuam na busca pelo desenvolvimento sustentável das comunidades nas quais estão inseridas.

Nos últimos tempos, os empreendimentos cooperados vêm enfrentando dificuldades em manter alguns desses princípios tais quais foram idealizados pelos pioneiros do cooperativismo. Este fato se explica, em parte, pela essência socialista pela qual estão imbuídos (ANTONIALLI; SOUKI, 2005). Com o avanço do capitalismo, as cooperativas operam em um ambiente de competitividade crescente. Assim, existem pressões, cada vez mais fortes, para que certos princípios (especialmente adesão livre e gestão democrática) sejam reformulados ou suplantados em face de uma administração mais racional, a qual possa colocar as cooperativas em melhores condições de competição frente às empresas tradicionais (PINHO, 1966; ZYLBERSZTAJN, 1994; PASCUCI et al., 2017).

É inegável a importância do cooperativismo enquanto instrumento de desenvolvimento social e econômico. Assim como também não se pode negar o fato de que, apesar dos avanços conquistados nestes mais de 170 anos, a doutrina cooperativista precisa evoluir e se adaptar a nova lógica competitiva na qual está inserida. Por outro lado, é igualmente fundamental que Estado e sociedade concentrem esforços para a criação de um ambiente cultural e institucional favorável, fator considerado primordial para o crescimento e consolidação do setor cooperativista (GAGLIARDI, 2009; LOPES, 2012).

\section{Cooperativismo Agroindustrial}

Sabe-se que existe uma série de particularidades, inerentes à atividade agroindustrial, que a tornam essencialmente mais complexa que outros setores. Fatores ligados a sazonalidades, variabilidade dos produtos, perecibilidade e regulação governamental, além de incertezas de ordem natural, fazem com que boa parte das modernas ferramentas de gestão se torne inadequada quando implantadas no agronegócio (BATALHA; SILVA, 2014; ARAÚJO, 2018). Assim, é preciso que a gestão dos empreendimentos agroindustriais seja focada na busca constante por eficácia e eficiência, adotando estratégias adaptadas à realidade do segmento e levando em consideração, não apenas aspectos internos de cada firma, mas, também, as relações entre os agentes ao longo de um sistema agroindustrial.

O fato é que as firmas atuantes no segmento agroindustrial têm se tornado cada vez mais consciente de que não operam de maneira isolada, mas que, sim, faz parte de uma ampla cadeia, cujo objetivo central é a geração de valor para o consumidor final (FERREIRA, 2009). Assim, é possível notar a emergência de conceitos tais como Supply Chain Management (BATALHA; SILVA, 2014) e Netchains (ILIOPOULOS et al., 2016), entre outros. Essas ferramentas de gestão representam a busca por uma atuação coletiva entre diversos agentes de um mesmo sistema agroindustrial, visando uma aproximação consistente aos mercados consumidores, que pode, em suma, tornar o sistema, como um todo, mais competitivo ante o cenário concorrencial globalizado.

Por outro lado, a persistente volatilidade presente nos mercados de commodities (BRIGGEMAN et al., 2011), aliada à crescente demanda mundial por alimentos (FAO, 2018; SAATH;

FACHINELLO, 2018) e à urgência na produção de combustíveis renováveis (LEITE; BATALHA, 2016) tem exercido crescentes pressões aos sistemas agroindustriais, exigindo níveis de competividade 
cada vez maiores. Tais níveis, só poderão ser atingidos se as firmas forem capazes de alcançar a eficácia e a eficiência de maneira coletiva, gerando sinergias e ganhos de escala. Deste modo, se torna evidente e ganha importância a coordenação entre os agentes do sistema.

Neste cenário, as cooperativas agroindustriais surgem como uma alternativa importante, graças ao seu potencial de coordenação das relações entre os cooperados e os demais agentes do sistema (DELARMELINA; SALES, 2016; ILIOPOULOS et al., 2016). Estudos recentes têm apontado que as cooperativas desempenham um papel de destaque no desenvolvimento agroindustrial de um país, sendo que, em sistemas desenvolvidos, é comum que estas sejam as grandes responsáveis pela produção e comercialização de gêneros de origem agropecuária (BIJMAN et al., 2012; ILIOPOULOS et al., 2016).

A organização cooperativa constitui um meio viável para a coordenação eficiente dos sistemas agroindustriais (BIALOSKORSKI NETO, 1999). Vez que esta pode participar de várias etapas do processo produtivo, apresenta as condições necessárias para estreitar as relações entre os diversos agentes envolvidos, facilitando as transações e, consequentemente, minorando os custos de transação envolvidos (BIALOSKORSKI NETO, 1999; DELARMELINA; SALES, 2016). Neste sentido, pode-se inferir que a organização cooperada agroindustrial, percebida como um nexo de contratos (COOK et al., 2004), constitui uma estrutura de governança, dotada de condições para exercer a coordenação em dois sentidos: horizontal, quando coordena as ações e esforços entre seus cooperados; e vertical, quando busca facilitar as relações entre os diversos agentes do sistema agroindustrial, com vistas ao ganho de eficiência conjunta.

Igualmente, as cooperativas representam, para os pequenos produtores rurais, um importante instrumento de inserção no sistema agroindustrial, bem como de acesso a mercados (BIALOSKORSKI NETO, 1999; PINTO et al., 2012; DELARMELINA; SALES, 2016). Tal acesso se dá em três frentes distintas: através de ganhos de escala (DELARMELINA; SALES, 2016), agregação de valor (BIALOSKORSKI NETO, 1999; GERTLER, 2001; GIMENES; GIMENES, 2007) e acesso a múltiplos canais de distribuição (PINTO et al., 2012; DEIMLING et al., 2015). Em geral, a participação em cooperativas agropecuárias também confere aos seus associados um poder de barganha o qual jamais poderiam experimentar atuando de forma isolada nos mercados (BIALOSKORSKI NETO, 1999; GIMENES; GIMENES, 2007; DELARMELINA; SALES, 2016). As cooperativas podem representar uma solução para o problema de eficiência econômica dos pequenos e médios produtores rurais, conferindo-lhes a possibilidade de competir com grandes empresas do segmento (FERREIRA, 2009).

Dadas as condições de maior complexidade relacionadas à atividade agropecuária, as cooperativas atuantes neste segmento assumem um papel ainda mais importante frente à gestão de riscos e volatilidade (BIALOSKORSKI NETO, 1999; MOREIRA et al., 2012; BRIGGEMAN et al., 2013). Ao participar de uma cooperativa o produtor rural reduz os riscos de sua atividade, especialmente aqueles relacionados à comercialização e oscilações abruptas de preços (BRIGGEMAN et al., 2013). A cooperativa representa uma forma de proteção contra os comportamentos oportunistas, uma vez que cuida da negociação de preços e comercialização em grandes volumes, desenvolvendo, também, devido à estabilidade da oferta, relações de longo prazo com os principais parceiros comerciais (DELARMELINA; SALES, 2016).

Em geral, tendo em vista a percepção da diminuição dos riscos associados à atividade, produtores rurais ligados às cooperativas possuem maiores incentivos para manter constante a sua produção (LEVIN, 1984). A estabilidade de oferta traz benefícios ao sistema agroindustrial como um todo, vez que aumenta a confiança entre os parceiros comerciais habituais e, ao mesmo tempo,

contribui para a diminuição da incidência de problemas ligados à interrupção sazonal de receitas (DELARMELINA; SALES, 2016). 
As cooperativas agroindustriais têm enfrentado importantes desafios nos. Para superá-los, a maioria delas precisa passar por profundas transformações, que, muitas das vezes, podem ser conflituosas em relação aos princípios doutrinários originais do cooperativismo (ANTONIALLI; SOUKI, 2005). Em verdade, somente através da profissionalização efetiva da gestão e da modernização dos mecanismos de tomada de decisão, as cooperativas agroindustriais poderão assumir, de maneira eficiente e eficaz, o seu papel na coordenação dentro dos sistemas agroindustriais.

Por fim, não se pode deixar de destacar o papel das cooperativas agroindustriais enquanto importantes instrumentos de desenvolvimento rural e regional (ALVES; LIMA, 2018). A atuação dos empreendimentos cooperados vai muito além da geração e distribuição de benefícios econômicos, pois, ao promover o fortalecimento dos laços entre os produtores rurais locais, elas fomentam o desenvolvimento do capital social e do associativismo nas comunidades em que atuam.

\section{Cooperativismo Agroindustrial no Centro-Oeste Brasileiro}

O cenário a ser descrito a seguir é baseado em dados e informações fornecidos pela Organização das Cooperativas Brasileiras (OCB), especialmente, suas unidades sediadas nos estados que compõem a Região Centro-Oeste, bem como pelo Instituto Brasileiro de Geografia e EstatísticaIBGE. No caso dos Estados de Goiás e Mato Grosso do Sul, as OCBs locais realizam um trabalho sistematizado de coleta de informações acerca da atividade cooperada, que resulta em documentos periódicos abrangentes, capazes de fornecer subsídios para a formulação de um retrato satisfatório a respeito do cooperativismo agroindustrial nestas localidades. No entanto, no estado de Mato Grosso, o que existe, no momento, é a intenção de realizar um trabalho semelhante, o qual teria, segundo informações da OCB-MT, previsão de publicação dos primeiros resultados em abril de 2019, o que, não acorreu até meados de maio, pelo menos. Assim, neste estado, já há uma dificuldade maior em obterem-se dados relativos ao cooperativismo agroindustrial. No Distrito Federal, a situação é ainda mais complicada, vez que não existe, sequer, iniciativa para a coleta sistematizada de dados.

Quanto às cooperativas agroindustriais brasileiras, Antonialli (2000) apontou, em seu estudo, algumas características particulares, que, por analogia, acredita-se que se aplicam às entidades baseadas na Região Centro-Oeste:

- Seguem os princípios doutrinários "rochdaleanos";

- Estão amparadas por legislação específica (Lei $5 \cdot 764 / 71$ ), sendo que cada cooperativa é regida por estatuto social próprio;

- Seus objetivos são pautados pela busca do equilíbrio entre as dimensões econômica e social;

- Os associados exercem o duplo papel de proprietários e usuários da organização cooperada;

- Os estatutos determinam eleições periódicas para a escolha de dirigentes, não podendo seu mandato ser superior a quatro anos;

- As cooperativas são geridas pelos próprios associados (autogestão);

- As iniciativas de profissionalização são, ainda, escassas; e

- O processo decisório é colegiado, o que pode tornar a tomada de decisão um processo lento e burocrático. 
Segundo dados da OCB-MS (2018), no Brasil, existem 1.555 cooperativas operando no segmento agroindustrial. Elas contam com, aproximadamente, 1 milhão de cooperados e empregam diretamente algo em torno de 164 mil pessoas, sendo responsáveis por $48 \%$ da produção agrícola nacional. Ressalta-se, ainda, que, segundo dados da OCB-MS (2018), as cooperativas possuem 20\% da capacidade estática de armazenagem em território brasileiro, o que corresponderia a 30 milhões de toneladas de grãos.

A Região Centro-Oeste, por sua vez, conta com 8 cooperativas agroindustriais, sediadas no Distrito Federal (OCB, 2019), 55 em Mato Grosso (OCB-MT, 2019), 74 em Goiás (OCB-GO, 2018) e 38 em Mato Grosso do Sul (OCB-MS, 2018), perfazendo um total de 175 entidades operando no segmento. Vale ressaltar que estes números levam em consideração apenas as cooperativas cujas matrizes estão instaladas nos Estados focalizados, existindo, em paralelo, um incontável número de filiais de cooperativas que vem de outras regiões e estão operando no Centro-Oeste.

De acordo com dados do Censo Agropecuário, existem 346.721 propriedades rurais no Centro-Oeste, sendo que destas, 45.869 ou 13,2\%, estão associados a cooperativas (IBGE, 2018). No entanto, apenas 13.171 estabelecimentos recebem orientação técnica cooperada. No Brasil, as cooperativas agropecuárias possuem, em média, 371 estabelecimentos associados. Enquanto isso, no Centro-Oeste, este número cai para apenas 249 propriedades por empreendimento. A área média dos estabelecimentos do Centro-Oeste é quase 3 vezes maior quando comparada ao Brasil como um todo, isso pode explicar, em parte, o menor número médio de propriedades associadas. Por outro lado, denota a amplitude da fronteira de crescimento para o cooperativismo agroindustrial na região.

Em 2013, de acordo com a OCB, havia 209 cooperativas agroindustriais ativas sediadas no Centro-Oeste, o que permite perceber uma redução de $16,2 \%$ no número de estabelecimentos em 4 anos. Assim, a despeito da aparente pujança do setor, há evidências de que existem problemas a explorar. Em parte, pode-se atribuir o fechamento de cooperativas agroindustriais à prolongada estagnação econômica pela qual o país vem passando. Por outro lado, a coleta rotineira de dados, promovida pelas OCBs de Goiás e Mato Grosso do Sul, levou à exclusão de cooperativas que já estavam inativas há algum tempo. No entanto, há que se considerar a situação sob uma ótica mais aprofundada, onde, certamente, repousam outras questões, mais particulares, relacionadas ao planejamento e gestão da atividade.

\subsection{Goiás}

O Estado de Goiás conta, com 152.089 propriedades rurais, dentre as quais 21.384 se encontram ligadas a cooperativas agroindustriais (IBGE, 2018). A média de propriedades associadas por cooperativa é, portanto, de 289. O número de cooperativas agroindustriais registradas se manteve praticamente estável entre 2013 e 2017, caindo de 76 para 74, sendo que, no ano de 2017, foi concedido apenas 1 registro para novo empreendimento nesse segmento (OCB-GO, 2018). Ainda assim, 34,4\% das cooperativas registradas na OCB-GO pertencem ao ramo agroindustrial.

Hoje, há, no território goiano, 31.764 cooperados filiados às organizações do ramo agroindustrial, representando 19,4\% do universo total (OCB-GO, 2018). Neste segmento, entre os cooperados, predominam os homens, com $86,8 \%$ de participação. As mulheres, por sua vez, representam $12,1 \%$, restando $1,1 \%$ correspondente a pessoas jurídicas.

Por outro lado, o ramo agroindustrial empregava, no final de 2017, diretamente, 5.529 pessoas, sendo responsável por 49,7\% dos empregos gerados por cooperativas em Goiás. É, portanto, de longe, o ramo que mais gera postos de trabalho nesse estado. Igualmente, entre os empregados predominam os homens, constituindo, em $2017,75 \%$ do quadro funcional das cooperativas agroindustriais sediadas em território goiano (OCB-GO, 2018). Apenas 15,8\% do pessoal possuía curso superior, havendo a predominância de colaboradores de nível médio, com 45,3\%. 
Se o número de cooperativas agroindustriais se manteve praticamente na estabilidade entre 2013 e 2017, o de cooperados, por sua vez, quase dobrou, experimentando um crescimento de $91 \%$ no mesmo período (OCB-GO, 2018). Esse fato denota o fortalecimento, ainda maior, das cooperativas já consolidadas, bem como a concentração crescente de cooperados nas maiores organizações.

Quanto às receitas, as cooperativas agroindustriais goianas obtiveram, em 2017, entradas brutas superiores a $\mathrm{R} \$ 5,6$ bilhões, ou $58,3 \%$ do faturamento total do cooperativismo no estado (OCB-GO, 2018), o que representou um crescimento de $25,8 \%$ em relação a 2013. No entanto, em 2017, o faturamento do segmento foi $\mathrm{R} \$ 426,8$ milhões inferior ao registrado no ano anterior. Já com relação à geração de tributos, as cooperativas do ramo agroindustrial foram responsáveis, também em 2017, por R\$219,2 milhões em impostos, resultando em um incremento de 5,7\% em comparação com o ano de 2013, ou 52,6\% de todos os tributos pagos pelo cooperativismo no estado. Descontando-se a contribuição ao Instituto Nacional do Seguro Social (INSS), feita pelos cooperados, o Imposto Sobre Circulação de Mercadorias e Serviços (ICMS) foi responsável por, aproximadamente, $60 \%$ dos impostos pagos pelas cooperativas do ramo agroindustrial.

O patrimônio líquido total das cooperativas agroindustriais goianas apresentou, no período de 2013 a 2017, um crescimento de 43\%, chegando ao valor de R\$ 2,13 bilhões (OCB-GO, 2018). Somente entre os dois últimos anos, o incremento foi de $27,5 \%$. Paralelamente, o capital social destas organizações também apresentou significativo crescimento no mesmo período, 36,1\%, totalizando R $\$ 1,08$ bilhão. O capital social corresponde a aproximadamente $60 \%$ da composição do patrimônio líquido das cooperativas do segmento agroindustrial. Os fundos de desenvolvimento e reserva, igualmente, apresentaram crescimentos importantes nos últimos 5 anos, $5.900 \%$ e $28,5 \%$, respectivamente. De acordo com a OCB-GO (2018), o aumento destes fundos é fundamentalmente estratégico para a promoção da solidez das cooperativas.

No que tange ao recebimento de grãos, as cooperativas agroindustriais goianas receberam 18,3 milhões de toneladas em 2017 , sendo que a soja representou $58 \%$ e o milho $41 \%$ do total, restando apenas $1 \%$ para o sorgo e outros grãos (OCB-GO, 2018). Entre os anos de 2014 e 2017, os recebimentos de soja tiveram um incremento de $191,7 \%$, sendo que, em 2017 , recebeu-se 5 vezes mais soja do que em 2016. O milho, por sua vez, teve o volume aumentado em 161,6\% nos mesmos 4 anos. Já os recebimentos de leite caíram significativamente entre 2013 e 2017, havendo uma redução de 21\%, de 677 para apenas 533 milhões de litros.

As cooperativas agroindustriais do estado de Goiás contavam, no final de 2017, com 177 profissionais técnicos direta e indiretamente contratados, dentre os quais: 71 agrônomos, 76 veterinários, 11 técnicos agrícolas, 13 zootecnistas e 6 técnicos em outras especialidades (OCB-GO, 2018). Houve, no período de 2013 a 2017, uma queda de $29,8 \%$ no número de profissionais ocupados nas equipes técnicas das cooperativas agroindustriais goianas. Este fato pode, em parte, ser explicado pelo prolongado período de desaquecimento da economia brasileira, iniciado em 2014.

Chama a atenção o fato de que $62 \%$ das cooperativas pertencentes ao segmento agroindustrial não realizaram qualquer tipo de auditoria no ano de 2017 (OCB-GO, 2018). Esse número é motivo de preocupação, haja vista que as auditorias são instrumento fundamental para a profissionalização e transparência da gestão dos empreendimentos cooperados. Elas constituem importante ferramenta de controle estratégico, já que permitem verificar o alinhamento entre o planejado e o executado.

Com relação à intercooperação, 55\% das cooperativas agropecuárias goianas consomem regularmente produtos e/ou serviços de outras cooperativas. As aquisições se concentram, principalmente, em serviços financeiros (cooperativas de crédito), produtos agropecuários (outras cooperativas do ramo) e planos de saúde (cooperativas de saúde) (OCB-GO, 2018). 
O valor investido pelas cooperativas do ramo agroindustrial para a concessão de benefícios sociais a empregados e cooperados, em 2017, foi de R\$22,3 milhões (OCB-GO, 2018). A maior parte desse valor foi alocada para a área de saúde. No entanto, a maioria dos empreendimentos deste segmento ainda não oferece benefícios sociais, nem aos colaboradores, nem aos cooperados.

O que se observou, nos últimos anos, apesar das dificuldades de ordem econômica, foi o crescimento e, principalmente, a consolidação do cooperativismo agroindustrial goiano. Os empreendimentos deste segmento, em geral, por meio da melhoria da eficiência operacional, se tornaram mais produtivos, o que lhes permitiu aproveitar melhor os recursos disponíveis. Se, por um lado, houve uma diminuição no número de cooperativas no ramo, aquelas que sobreviveram tem prosperado e se fortalecido. Por este motivo, tem-se observado uma maior concentração da atividade nas grandes cooperativas. As 10 maiores cooperativas do segmento contavam, em 2017, com 73,5\% dos cooperados e 82,8\% do patrimônio líquido total dos empreendimentos.

A Cooperativa Agroindustrial dos Produtores Rurais do Sudoeste Goiano (COMIGO), sozinha, possuía, em $2017,22,7 \%$ dos cooperados no segmento e $70 \%$ do patrimônio líquido. A COMIGO, fechou o ano de 2018 com 7.568 cooperados, 2.471 funcionários e um faturamento de R\$ 4,3 bilhões (COMIGO, 2019).

\subsection{Mato Grosso do Sul}

Segundo dados do Censo Agropecuário (IBGE, 2018), existem, no estado de Mato Grosso do Sul, 70.710 propriedades rurais, dentre as quais 11.885 estão filiadas a cooperativas agroindustriais. Sendo assim, a média de propriedades por empreendimento é de 312, um pouco superior à registrada no estado de Goiás. Dentre todas as cooperativas filiadas à OCB-MS, 34,2\% atuam no segmento agroindustrial.

Oficialmente, entre 2017 e 2018, houve uma queda de 19,1\% no número de empreendimentos agroindustriais cooperados sul-mato-grossenses (OCB-MS, 2019). No entanto, na prática, a quantidade de cooperativas tem permanecido estável na última década, haja vista que a diminuição marcante no quantitativo é decorrente da iniciativa Panorama do Cooperativismo, que excluiu, no final de 2018 cooperativas que já não estavam em atividade há vários anos. Essa constatação é corroborada pelo fato de que $97 \%$ das cooperativas agroindustriais ativas, sediadas em Mato Grosso do Sul, estão operando há mais de 5 anos, sendo que $28 \%$ delas estão no mercado há mais de 30 anos (OCB-MS, 2018). Deste modo, observa-se que, assim como no estado de Goiás, o cooperativismo agroindustrial sul-mato-grossense passa por um período de consolidação e expansão dos empreendimentos tradicionais.

As 38 cooperativas do ramo agroindustrial, sediadas em Mato Grosso do Sul, contam com 20.882 cooperados, que representam $10 \%$ do total de associados do estado. Elas empregam, diretamente, 4.657 pessoas, ou $59,6 \%$ de todo pessoal ocupado pelo cooperativismo sul-matogrossense (OCB-MS, 2018), sendo as grandes geradoras de postos de trabalho no estado.

Dentre as cooperativas agroindustriais sul-mato-grossenses, $37 \%$ delas se dedicam à produção, armazenagem e/ou beneficiamento de grãos (soja, milho, sorgo e algodão), totalizando 47 mil toneladas em 2017 (OCB-MS, 2018). Laticínios, varejo e hortifrutigranjeiros, cada um, representam a atividade principal para 13\% dos empreendimentos. Os ramos de insumos e proteína animal contam com $9 \%$ cada, enquanto representação comercial fica com os $6 \%$ restantes.

Entre 2015 e 2017, o patrimônio líquido total dos empreendimentos cooperados agroindustriais do estado de Mato Grosso do Sul, apresentou expansão de 18\%, saltando de R\$ 667 para R\$ 797 milhões (OCB-MS, 2018). Ressalta-se que este número leva em consideração apenas as cooperativas cujas matrizes estão instaladas em território sul-mato-grossense. À primeira vista os números parecem animadores, no entanto, causam certa preocupação quando comparados aos 
ramos de saúde e crédito, cujos patrimônios líquidos se expandiram e 59 e $87 \%$ respectivamente no mesmo período.

Com relação aos ativos, que representam a soma dos bens, valores, créditos e direitos, as cooperativas agroindustriais sediadas em Mato Grosso do Sul apresentaram um crescimento de 9\% no período compreendido entre 2015 e 2017 (OCB-MS, 2018). Em números absolutos, os valores partiram de $\mathrm{R} \$ 2,52$ para $\mathrm{R} \$ 2,75$ bilhões dentro do intervalo de tempo observado. Chama a atenção o fato de que, em 2016, este valor correspondia a R\$2,9 bilhões, ou seja, se comparados apenas os 2 últimos anos da série, este índice se encontrará, na verdade, em viés de baixa.

As cooperativas agroindustriais sul-mato-grossenses faturam, em 2017, R\$ 7,8 bilhões, o que representou um crescimento de 17,5\% em comparação ao ano de 2015 (OCB-MS, 2018). O fato de que, somente entre 2015 e 2016 , esse número se expandiu em $15 \%$, pode apontar, assim como aconteceu com os ativos, a partir de 2017, uma tendência de queda no desempenho das cooperativas focalizadas.

Quanto às sobras, os valores saltaram de $\mathrm{R} \$ 30$ para $\mathrm{R} \$ 38$ milhões, no período de 2015 a 2017, apresentando crescimento de $27 \%$. No entanto, em 2016, registraram-se perdas de, aproximadamente, R\$1 milhão (OCB-MS, 2018). Levando-se em consideração que o valor dos ativos sofreu diminuição de 5,2\% no biênio 2016/2017, é plausível inferir-se que a melhoria do desempenho no quesito sobras, percebida em 2017, pode ter sido financiada à custa da redução de ativos e não do ganho de eficiência operacional.

A OCB-MS (2018) atribui o aparente desaquecimento do cooperativismo agroindustrial sulmato-grossense, percebido entre 2016/2017, a situação econômica enfrentada pelo Brasil desde 2014. Entretanto, há que se considerar a existência de fatores de cunho gerencial, estratégico e/ou operacional, que podem estar representando um entrave ao desenvolvimento do pleno potencial da atividade no estado.

\subsection{Mato Grosso}

Existem, de acordo com informações do Censo Agropecuário (IBGE, 2018), 118.676 propriedades rurais estabelecidas no estado de Mato Grosso. Destas, 12.047 encontram-se associadas a cooperativas agroindustriais. A média de propriedades por empreendimento é, portanto, 219, número bastante inferior ao registrado no Mato Grosso do Sul. Nota-se, ainda que, em 2017, 38,2\% das cooperativas registradas na OCB-MT pertenciam ao segmento agroindustrial.

No período de 2013 a 2017, o número de cooperativas agroindustriais registradas junto à OCB-MT (2018) sofreu uma diminuição de 19,1\%, caindo de 68 para apenas 55. Em termos percentuais, a diminuição no número de empreendimentos ativos é exatamente a mesma que aquela percebida no estado de Mato Grosso do Sul entre 2015 e 2017. Assim, por analogia, poderia se inferir que, igualmente, essa minoração numérica estaria ligada à exclusão de empreendimentos inativos há longo período. No entanto, a queda, em Mato Grosso, aconteceu de maneira gradativa ano a ano, o que, possivelmente, é um indicativo de que, neste estado, a explicação para o fenômeno seria outra. A divulgação do Censo do Cooperativismo Mato-Grossense 2018, que estava prevista para abril de 2019 e, até o momento, não ocorreu, seria de grande ajuda para a verificação da continuidade desta tendência, bem como sua melhor compreensão.

O número de cooperados do segmento, por sua vez, também apresentou diminuição de 12,9\%, em Mato Grosso, entre 2013 e 2017 (OCB-MT, 2018). Se comparado ao crescimento no número de cooperados do ramo, registrado no estado de Goiás no mesmo período, que foi de $91 \%$, percebese uma tendência marcantemente negativa neste quesito. $\mathrm{O}$ crescimento geral do universo de cooperados, somando-se todos os ramos operantes em Mato Grosso, também cresceu 46,8\% no 
intervalo 2013-2017, evidenciando, mais uma vez, estagnação do segmento agroindustrial neste estado. Três prováveis causas para este fenômeno poderiam ser: maior concentração de terras; aumento da eficiência e escala individuais dos produtores, levando-os à independência com relação às cooperativas, e/ou; experiência negativa, decepção pessoal com relação aos empreendimentos que não deram certo. No entanto, somente com pesquisas mais aprofundadas, seria possível confirmar ou excluir essas possibilidades.

O número de empregados diretos nas cooperativas agroindustriais mato-grossenses, por sua vez, percebeu um aumento de $22,8 \%$ entre 2013 e 2017 , saltando de 1.989 para 2.576 colaboradores. $\mathrm{O}$ crescimento no número de postos de trabalho, assim como aconteceu no estado de Goiás, pode ser um indicativo de que as maiores e mais tradicionais cooperativas também estão se consolidando em Mato Grosso. O quantitativo total de empregados em todos os ramos de cooperativas matogrossenses, por sua vez, cresceu apenas $5 \%$ no intervalo 2013/2017, sendo que, em 2017, o segmento agroindustrial era responsável por 31,2\% dos postos de trabalho ativos. Diferentemente de Goiás e Matogrosso do Sul, o ramo agroindustrial não é o que mais emprega em Mato Grosso, perdendo para o segmento de crédito.

De acordo com dados pesquisados junto à OCB-MT (2019), o patrimônio líquido total das cooperativas agroindustriais sediadas no estado de Mato Grosso, somava, no fechamento do exercício de 2017, R\$ 766 milhões. Enquanto isso, os ativos perfaziam o total de R\$ 233 milhões.

Conforme se pôde observar, o cooperativismo agroindustrial mato-grossense apresenta algumas particularidades em relação aos outros estados da região Centro-Oeste. No entanto, a escassez de dados oficiais torna difícil a compreensão dos fenômenos relatados. Pesquisas de campo serão necessárias para a elucidação definitiva do tema.

\subsection{Distrito Federal}

O Distrito Federal possuía, no ano de 2017, 5.246 propriedades rurais, dentre as quais 553, estavam, de alguma forma, ligadas às cooperativas agroindustriais (IBGE, 2018). Assim, tem-se uma média de 69 propriedades por empreendimento. No entanto, este número pode ter algum nível de distorção, vez que é possível que haja propriedades, do entorno do Distrito Federal, associadas às cooperativas candangas.

Segundo informações da OCB-DF (2018), existem 8 cooperativas agroindustriais ativas, com sede no Distrito Federal. Operando na produção, armazenagem e beneficiamento de grãos (milho, soja, feijão) tem-se: Cooperativa Agropecuária da Região do Distrito Federal (COOPA/DF) e Cooperativa Agrícola do Rio Preto (COARP); no segmento de laticínios: Cooperativa Agropecuária de São Sebastião (COPAS); produzindo hortaliças: Cooperativa Agrícola da Região de Planaltina Cootaquara (COOTAQUARA) e Cooperativa Feirantes; na produção e abate de aves: Cooperativa de Negócios Ecoagropecuários (CIO DA TERRA); e no segmento de orgânicos: Cooperativa dos produtos do Mercado Orgânico de Brasília (COOPERORG). Existem, ainda, 5 filiais de cooperativas de outros estados estabelecidas no Distrito Federal. Elas atuam no ramo de laticínios e proteína animal, havendo, também, o1 estabelecimento voltado para a produção vitícola.

Infelizmente, os dados disponíveis com relação ao cooperativismo agroindustrial no Distrito Federal são bastante escassos. Segundo informações buscadas junto à OCB-DF, não há iniciativa no sentido de promover a coleta sistematizada de informações. Assim, o único meio para aquisição de dados mais esclarecedores a respeito da atividade é a pesquisa de campo. Como o número de estabelecimentos é reduzido, pode ser que seja possível a realização de um trabalho censitário. 


\section{Conclusões}

A realização deste estudo proporcionou evidências de que o cooperativismo foi e é de grande importância para diversas áreas da atividade humana, em especial para o segmento agroindustrial. No entanto, a história tem mostrado que os princípios e a doutrina cooperativista, tal qual foram idealizados pelos Pioneiros da Rochdale, já não atendem integralmente as necessidades dos mercados modernos, dentro dos quais as cooperativas precisam cuidar cada vez mais de sua dimensão empresarial para conseguirem sobreviver e prosperar. Ou seja, a chave para atingir os anseios sociais, está crescentemente ligada à capacidade da cooperativa em desempenhar, de forma eficiente e eficaz, seu papel empresarial.

Na região Centro-Oeste, o cooperativismo agroindustrial representa papel de destaque para o agronegócio e economia locais. No entanto, há evidencias de problemas que tem levado à diminuição do número de cooperativas, bem como à estagnação de alguns indicadores. O cenário que se desenha mostra tendências à concentração no setor agroindustrial, onde as grandes e tradicionais cooperativas aparentam estar ficando cada vez maiores e mais sólidas, especialmente, no que tange à produção de grãos. Enquanto isso, as pequenas cooperativas, normalmente com pouco tempo de experiência na atividade, parecem estar encontrando dificuldades para sobreviver e prosperar. Encontrar a chave para esta questão pode significar o fornecimento de subsídios para o desenvolvimento sustentável do cooperativismo agroindustrial do Centro-Oeste e do Brasil.

Como agenda de pesquisa, sugere-se a realização de estudos que visem à compreensão dos fatores de sucesso importantes para as cooperativas agroindustriais, bem como à medição de sua capacidade competitiva em termos empresariais e sociais, além da busca por ferramentas de gestão e planejamento que possam ser adaptados especialmente para os empreendimentos agroindustriais cooperados.

\section{Referências}

ACI - Aliança Cooperativa Internacional. Cooperative identity, values \& principles. Disponível em: www.ica.coop/en/cooperatives/cooperative-identity. Acesso em: 04 dez. 2018.

ALTMAN, M. Cooperatives, History and Theories of. In: International Encyclopedia of Civil Society. Victoria University of Wellington, Wellington, New Zealand: 2016.

ANTONIALLI, L. M.; SOUKI, G. C. Princípios cooperativistas e modelo de gestão: um estudo sobre conflitos de interesses entre grupos de produtores rurais. In: Anais do XLIII CONGRESSO DA SOBER: Instituições, Eficiência, Gestão e Contratos no Sistema Agroindustrial. Brasília: SOBER, 2005.

AROCAS. E. P.; RUBIO, M. R.; ARMENGOL, G. M. Situación Actual Del Cooperativismo en Chile. Santiago: Universidad de Chile, 2003.

AZERÊDO, R. F.; BAGENETA, J. M.; CHRISTOFFOLI, P. I. Territorialização do Cooperativismo Agrário Frente à Consolidação do Modelo do Agronegócio: Estudos de Casos na Argentina e Brasil. Revista Pegada, v. 19, n.1, p. 118-149, 2018.

BONIN, J.; JONES, D. C.; PUTTERMAN, L. Theoretical and Empirical Studies of Producer Cooperatives: Will Ever the Twain Meet? Journal of Economic Literature, v. 31, n. 3, p. 1290-1320, 1993. 
COMIGO - Cooperativa Agroindustrial dos Produtores Rurais do Sudoeste Goiano. Quem somos. Disponível em: comigoserver.com.br/empresa. Acesso em: 04 fev. 2019.

CONAB - Companhia Nacional de Abastecimento. Acompanhamento da Safra Brasileira: Grãos. v. 6 - Safra 2018/19, n. 8 - Oitavo levantamento. Brasília: CONAB, 2019a.

CONAB - Companhia Nacional de Abastecimento. Acompanhamento da Safra Brasileira: Cana-deaçúcar. v. 6 - Safra 2019/20, n.1 - Primeiro levantamento. Brasília: CONAB, 2019b.

DELARMELINA, N.; SALLES, A. O. T. Um estudo sobre a comercialização da produção de cooperativas agropecuárias sob a ótica da Teoria dos Custos de Transação. Custos e @gronegócio on line, v. 12, n. 4, p. 34-71, out/dez, 2016.

EMBRAPA - Empresa Brasileira de Pesquisa Agropecuária. Anuário do Leite 2018: Indicadores, tendências e oportunidades para quem vive no setor leiteiro. Brasília: EMBRAPA, 2019.

FAIRBAIRN, B. The Meaning of Rochdale: The Rochdale Pioneers and the Co-operative Principles. Saskatoon, Canada: Center for the Study of Cooperatives, Occasional Paper Series, 1994.

GAGLIARDI, F. Firm Performance and Institutional Context: a theoretical exploration with evidence from the Italian cooperative sector. Tese ( $\mathrm{PhD}$ in Economics), University of Hertfordshire, Hertfordshire, 2009.

IBGE - Instituto Brasileiro de Geografia e Estatística. Brasil em síntese. Disponível em: brasilemsintese.ibge.gov.br/comercio/numero-de-empresas-por-segmento-do-comercio.html.

Acesso em: 03 dez. 2018.

IBGE - Instituto Brasileiro de Geografia e Estatística. Censo Agropecuário 2017. Brasília: IBGE, 2018.

LOPES, J. A. V. Cooperativismo contemporâneo: caminho para a sustentabilidade. Brasília: Editora Confebras, 2012.

MILES, M. P.; WHITE, J. B.; MUNILLA, L. S. Strategic planning and agribusiness: an exploratory study of the adoption of strategic planning techniques by co-operatives. British Food Journal, v. 99, n. 11, p. 401-408, 1997.

MOREIRA, V. R.; SILVA, C. L. D.; MORAES, E. A. D.; PROTIL, R. M. O cooperativismo e a gestão dos riscos de mercado: análise da fronteira de eficiência do agronegócio paranaense. Revista de Economia e Sociologia Rural, v. 5o, n. 1, p. 51-68, 2012.

OCB - Organização das Cooperativas Brasileiras. Fundamentos do Cooperativismo. Brasília: OCB, 2017b.

OCB - Organização das Cooperativas Brasileiras. História do Cooperativismo. Disponível em: www.ocb.org.br/historia-do-cooperativismo. Acesso em: 04 dez. 2018.

OCB - Organização das Cooperativas Brasileiras. Notícias. Disponível em: www.ocb.org.br/site/agencia_noticias/index.asp. Acesso em: 29 dez. 2017 a.

OCB - Organização das Cooperativas Brasileiras. Notícias. Disponível em: agrobrasilia.com.br/imprensa/noticias/461-sistema-ocdf-sescoop-df-apoia-as-cooperativasagropecuarias.html. Acesso em: 03 abr. 2019. 
OCB - Organização das Cooperativas Brasileiras. O que é cooperativismo? Disponível em: www.ocb.org.br/o-que-e-cooperativismo. Acesso em: 04 dez. $2018 \mathrm{~b}$.

OCB/MS - Organização das Cooperativas Brasileiras Unidade Mato Grosso do Sul. Panorama do Cooperativismo Sul-Mato-Grossense 2018. Campo Grande: OCB/MS, 2018.

OCB/MT - Organização das Cooperativas Brasileiras Unidade Mato Grosso. Informativo Mato Grosso Cooperativo. Cuiabá: OCB/MT, maio/2019.

OCB/MT - Organização das Cooperativas Brasileiras Unidade Mato Grosso. Evolução do Cooperativismo MT 2018. Disponível em: ocb.ocbmt.coop.br/ cooperativismo/evolucao-docooperativismo-mt/5749. Acesso em: 20 abr. 2019.

OCB/GO - Organização das Cooperativas Brasileiras Unidade Goiás. Censo do Cooperativismo Goiano 2018. Goiânia: OCB/GO, 2018.

OCB/DF - Organização das Cooperativas Brasileiras Unidade Distrito Federal. Notícias. Disponível em: agrobrasilia.com.br/imprensa/noticias/461-sistema-ocdf-sescoop-df-apoia-as-cooperativasagropecuarias.html. Acesso em: 20 abr. 2019.

PASCUCI, L.; LORENZI, G. de A.; CASTRO, S. C. de. Princípios Cooperativistas e Conflitos de Interesses: Um Estudo Comparativo. Revista Eletrônica Estácio Papirus, v. 1, n. 1, p. 1-13, 2017.

PINHO, D. B. A doutrina cooperativa nos regimes capitalista e socialista. 2. ed. São Paulo: Pioneira, 1966.

RICCIARDI, L.; LEMOS, R. G. de. Cooperativa, a empresa do século XXI: como os países em desenvolvimento podem chegar a desenvolvidos. São Paulo: LTC, 2000.

RIOS, G. S. L. O que é cooperativismo? 2. ed. São Paulo: Brasiliense, 2007.

SCHNEIDER, J. E. O Cooperativismo Agrícola na Dinâmica Social do Desenvolvimento Periférico Dependente: O Caso Brasileiro. In: LOUREIRO, M. R. G. (Org.). Cooperativas Agrícolas e Capitalismo no Brasil. São Paulo: Cortez: Autores Associados, 1981. p. 11-40.

SCOPINHO, R. A. Sobre Cooperação e Cooperativas em Assentamentos Rurais. Psicologia \& Sociedade, v. 19, n. 1, p. 84-94, 2007.

SESCOOP - Serviço Nacional de Aprendizagem do Cooperativismo. Números. Disponível em: www.ocb.org.br/site/sescoopatuacao_em_numeros.asp. Acesso em: 02 dez. 2018.

SESCOOP-RS - Serviço Nacional de Aprendizagem do Cooperativismo do Estado do Rio Grande do Sul. Notícias. Disponível em: www.sescooprs.coop.br/noticias/. Acesso em: 03 dez. 2018.

THOMPSON, A. Compliance with agreements in cross-cultural transactions: Some analytical issues. Journal of International Business Studies, v. 27, n. 2, p. 375-390, 1996.

ZEULI, K. A.; CROPP, R. Cooperatives: principles and practices in the 21st Century. Madison: University of Wisconsin Center for Cooperatives, 2008.

ZYLBERZTAJN, D. Organização de Cooperativas: desafios e tendências. Revista de Administração, São Paulo, v. 29, n. 3, p. 23-32, 1994. 